\title{
Specular microscopy of the corneal endothelium
}

\author{
G. D. STURROCK, E. S. SHERRARD, AND N. S. C. RICE \\ From the Pocklington Eye Transplantation Research Unit, Institute of Ophthalmology, London, and \\ Moorfields Eye Hospital, City Road, London
}

SUMMARY The endothelium of the normal corneas of 67 human subjects was studied in vivo with the specular microscope in order to quantify the method as a means of sampling the cell density of the tissue. It was found that (1) axial cell counts of the endothelium are reproducible in the same cornea after an interval of time; (2) the cell counts of the centre and periphery of the same cornea are similar; (3) the axial cell counts of pairs of eyes are similar; and (4) there is a gradual reduction of cell number with increasing age. The significance of these data is discussed.

Although it is possible to observe the individual cells of the corneal endothelium with the use of the biomicroscope and specular illumination (Vogt, 1919), eye movements and the limited magnification available virtually preclude the use of this technique for systematic study of the endothelium. These problems have been largely overcome by the introduction of the specular microscope (Maurice, 1968), which was subsequently adapted for clinical use by replacing the original water immersion lens with a dipping cone objective which applanates the cornea (Laing et al., 1975). With this instrument it is possible to examine and photograph the corneal endothelium at high magnification in vivo. Several authors have published their findings with the clinical specular microscope (Laing et al., 1976a, b; Bourne and Kaufman, 1976a, b, c; Bourne et al., 1976), and the optical principles have been discussed (Bourne and Enoch, 1976). Recently the use of an auxiliary lens to obtain a wider field of view has been described (Sherrard, 1976).

The purpose of the present study was to quantify the method of sampling corneal endothelial cell density with the specular microscope. Endothelial cell counts were performed on 67 subjects of various ages and the following 4 parameters were investigated-the reproducibility of axial cell counts, the relationship between axial and peripheral cell counts in the same eye, the relationship between axial cell counts from pairs of eyes, and the variation in axial cell density with age.

\section{Materials and methods}

APPARATUS AND PHOTOGRAPHY

The construction of the prototype specular micro-

Address for reprints: Mr G. D. Sturrock, FRCS, Universitäts Augenklinik, Mittlerestrasse 91, 4056 Basle, Switzerland scope used in this study is shown in Figs. 1 and 2. Kodak Tri-X film (ASA 400) was used for all photographs. The film contrast was increased by force-developing with Ilford Contrast FF developer, diluted 1 in 4 , for $2 \frac{1}{2}$ minutes at $20^{\circ} \mathrm{C}$, followed by normal fixing and printing. Specular photomicrographs of corneal endothelium are shown in Fig. 3.

Between 7 and 10 randomly selected areas of endothelium were photographed in the axial region of 1 or both corneas of all subjects. After an interval of some weeks 16 subjects were rephotographed. In 9 subjects the peripheral endothelium was also photographed at 2 sites, 3.5 to $4 \mathrm{~mm}$ from the nasal and temporal limbus respectively, in the horizontal meridian.

The pressure exerted by the objective on the subject's cornea was repeatedly checked during each photographic session. This was facilitated by the position of the viewing ocular, which projected at right-angles from the microscope, thus enabling the photographer to sit close-up beside the subject. Apart from the production of transient punctate epithelial erosions no corneal damage was caused by specular microscopy.

\section{CALIBRATION AND CELL COUNTING}

The specular microscope was calibrated by photographing a graticule mounted $0.5 \mathrm{~mm}$ from the dipping cone objective, the interspace being filled with saline. A photograph of the graticule was back-projected on to a screen from the same fixed distance at which the photographs of the corneal endothelium were subsequently projected. The film magnification was measured as $47.5 \times$ and the total linear magnification on the screen was found to be $358 \times$.

Cell counting was performed by making film contact prints from the negatives and back-projecting 


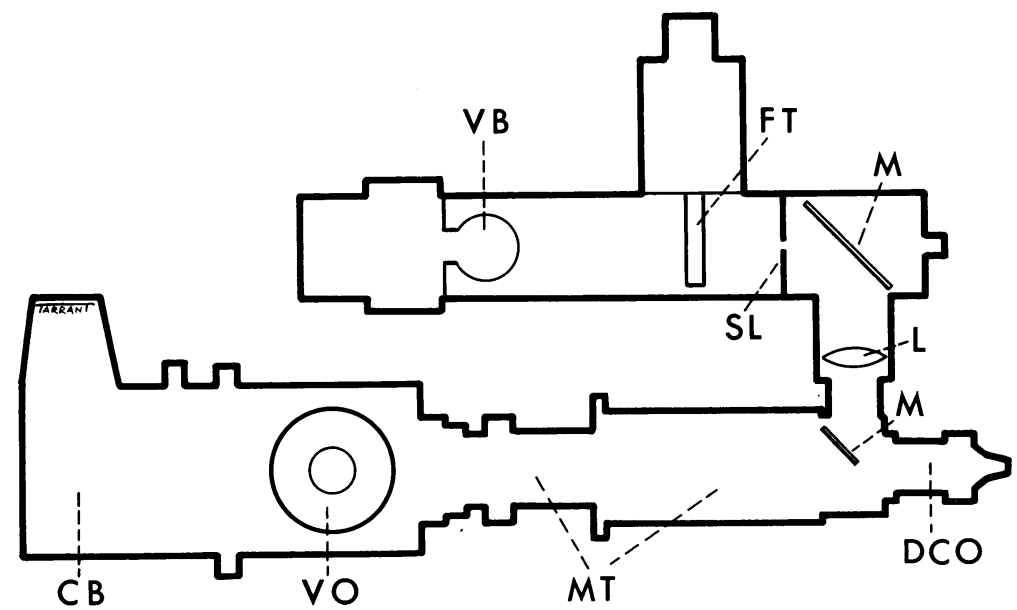

Fig. 1 Diagram of specular microscope. VB: rheostatcontrolled $15-W$ viewing bulb; FT: parfocal 60-W/S Xenon flash tube; $S L$ : adjustable slit aperture; $M$ (upper): adjustable mirror; $L:$ 20-dioptre lens; $M$ (lower): fixed mirror; DCO: Nikon $\times 20$ dipping cone objective; $M T$ : microscope tube; VO: viewing ocular (projecting at right-angles); CB: camera body

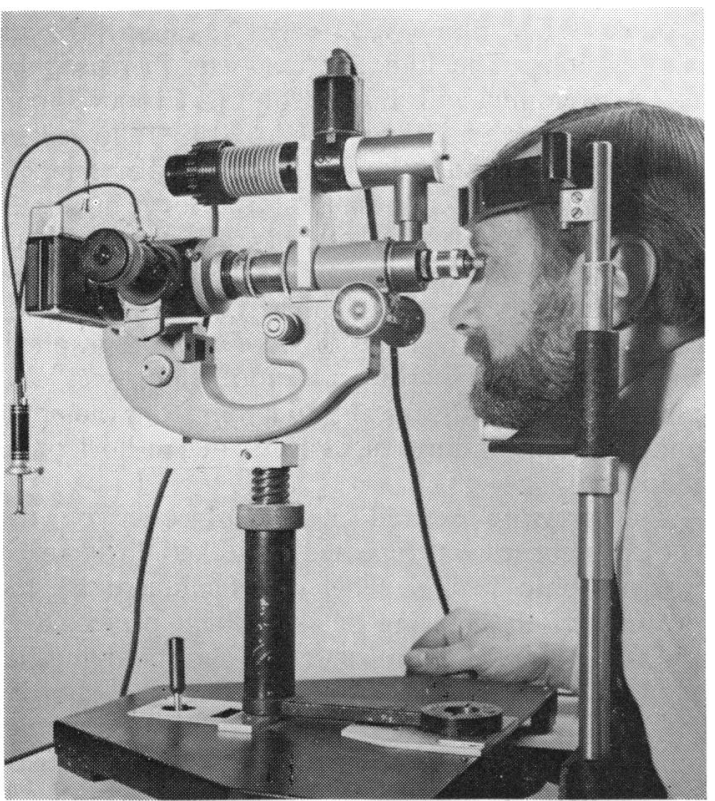

Fig. 2 Specular microscope mounted on slit lamp base and aligned with subject's left cornea

them on to the screen at the linear magnification of $358 \times$ established above. A rectangle of known area was placed on the screen, and the number of cells enclosed by the rectangle was counted. Cells touching the left-hand side and top of the rectangle were excluded, while cells touching the right-hand side and bottom were included in the count. Four different sizes of rectangle were available because the area of cells which could be counted was variable owing to the presence of hazy areas or dark folds on some photographs. The largest rectangle was used wherever possible to include the greatest number of cells. In order to reduce counting errors a clear celluloid sheet was placed over the counting rectangle, and each cell was marked with an ink dot as it was counted. The number of cells counted per photograph varied between 40 and 100 .

Owing to regional variations in endothelial cell density the 7 to 10 photographs taken per cornea recorded a range of cell counts from which the mean cell count for each cornea was calculated.
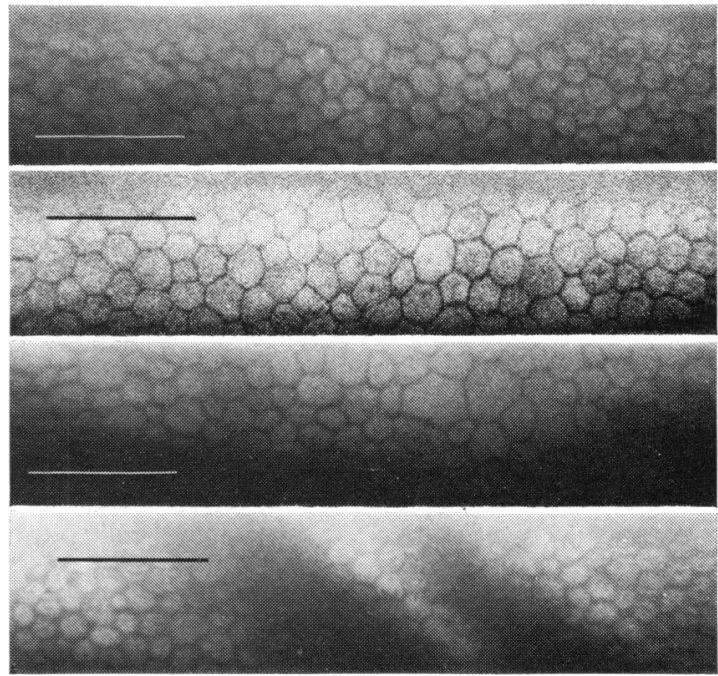

Fig. 3 Specular endothelial photographs. (a) Small uniform cells. Density 3100 cells $/ \mathrm{mm}^{2}$. Female 13 years. (b) Larger cells, fairly regular in size. Density 1980 cells $/ \mathrm{mm}^{2}$. Female 76 years. (c) Marked variation in cell size. Density 2080 cells $/ \mathrm{mm}^{2}$. Female 61 years. (d) Dark posterior corneal wrinkles due to dipping cone objective. Density 2900 cells $/ \mathrm{mm}^{2}$. Male 62 years. Bar $=100 \mu \mathrm{m}$ 
Fig. 4 Original mean cell count (cell count 1) plotted against repeat count (cell count 2) from 16 eyes to demonstrate reproducibility of counting technique
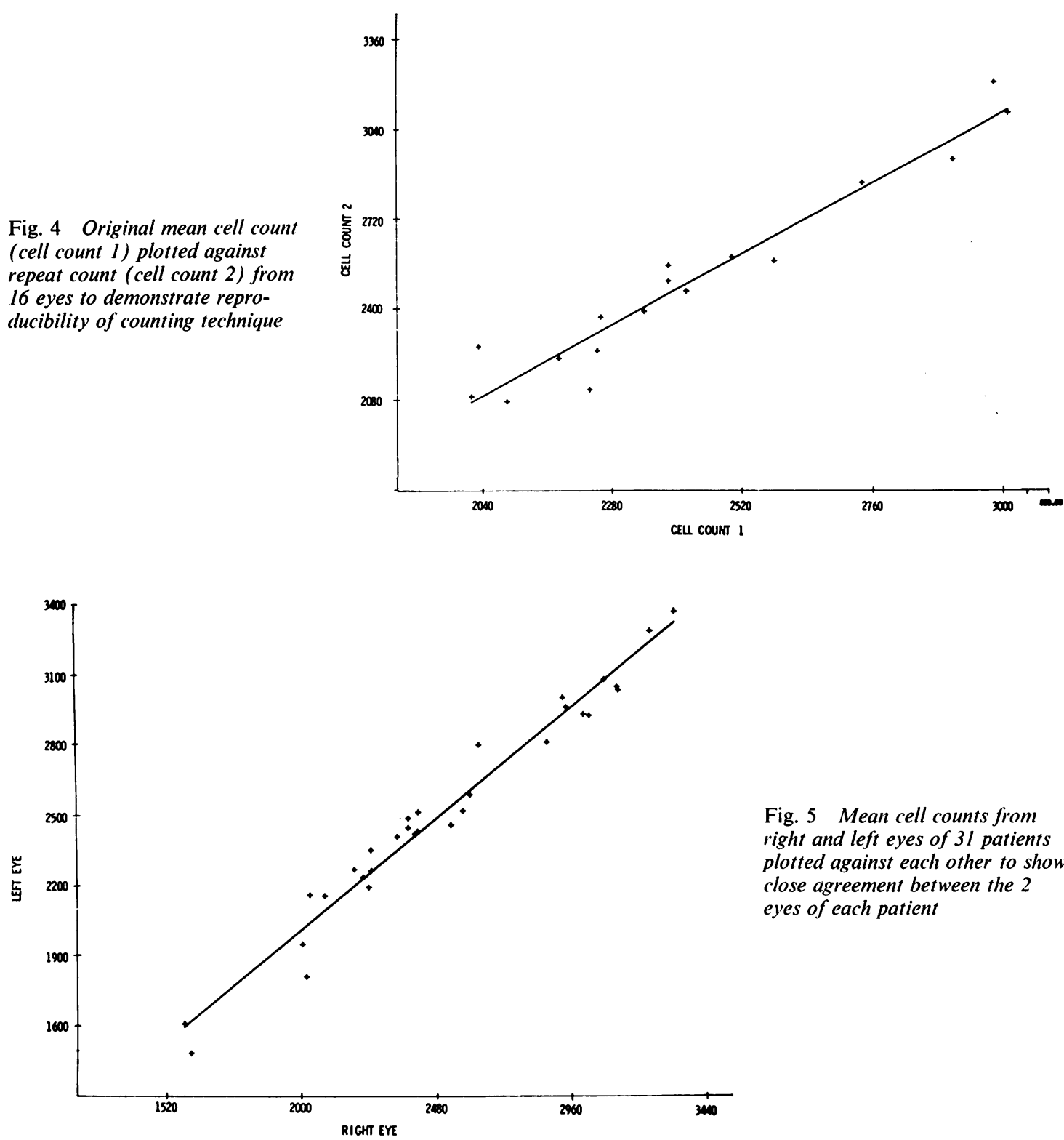

Fig. 5 Mean cell counts from right and left eyes of 31 patients plotted against each other to show close agreement between the 2 eyes of each patient

\section{SUBJECTS}

The endothelial cell counts presented here were obtained from hospital patients, the majority of whom were awaiting surgery for squint, obstructed lacrimal drainage, retinal detachment, or cataract. One of both eyes of each subject were included if prior biomicroscopic examination revealed a healthy clean cornea without endothelial guttae and no signs of inflammation, past or present, in the anterior segment. Eyes with a history of blunt or penetrating trauma, previous surgery, uveitis, or glaucoma were excluded. Eyes with uncomplicated senile lens opacities were included in the study.

\section{Results}

REPRODUCIBILITY

Axial endothelial cell counts were performed on 1 eye each of 16 subjects ( 8 males, 8 females, aged 48 to 52 years), and after an interval of $3 \frac{1}{2}$ to 20 weeks (average 7 weeks) the same eyes were rephotographed and the cells recounted. A comparison 


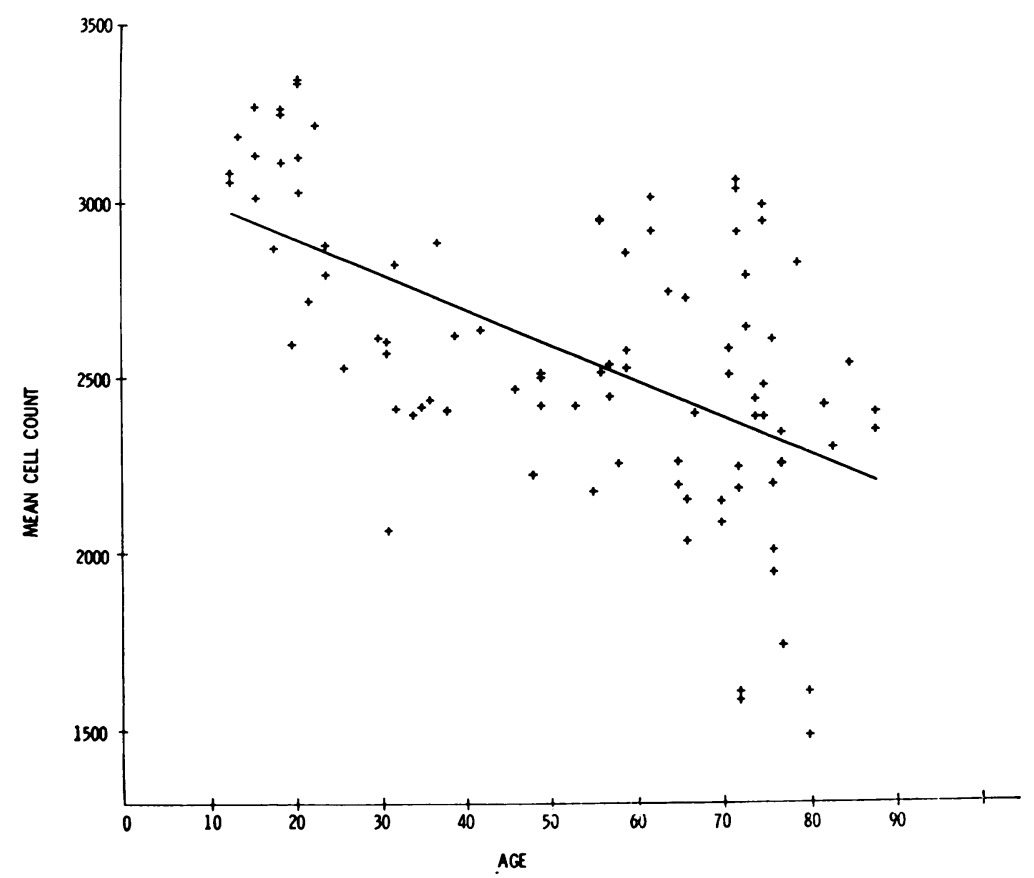

Fig. 6 Graph showing decrease in mean endothelial cell count with increasing age; 97 eyes

between the first and second mean cell counts for each eye (Fig. 4) showed a high degree of reproducibility $(\mathrm{P}<0 \cdot 001)$.

\section{AXIAL VERSUS PERIPHERAL COUNTS}

In 9 eyes (9 subjects, aged 20 to 85 years) endothelial cell counts were performed at 3 different sites on the cornea-in the axial region and 3.5 to $4 \mathrm{~mm}$ from the nasal and temporal limbus respectively, in the horizontal meridian. A comparison between the mean axial, nasal, and temporal counts showed the following relationships: Axial count $2.8 \%<$ nasal count $(\mathrm{P}<0.02)$; axial count $3.6 \%<$ temporal count $(\mathrm{P}<0.005)$; nasal count $0.8 \%<$ temporal count $(\mathrm{P}<0.005)$.

\section{RIGHT/LEFT CONCORDANCE}

Axial endothelial cell counts were performed on both eyes of 31 subjects (15 males, 16 females, aged 13 to 88 years). A comparison between the mean cell counts from the right and left eyes of each subject (Fig. 5) showed close agreement $(P<0.001)$.

\section{COUNT VERSUS AGE}

The relationship between axial cell count and age was studied in a group of 67 subjects comprising 33 males and 34 females, aged between 13 and 88 years. Both eyes were photographed in 30 subjects and only 1 eye in the remainder, so that a total of 97 mean cell counts were plotted against age (Fig. 6). The mean cell count was found to decrease significantly
$(\mathrm{P}<0.001)$ with increasing age of the subject. However, a broad range of mean cell counts was found in all age groups, as can be seen from the graph.

The scatter of the 7 to 10 different cell counts recorded from each individual cornea was quantitated by expressing the difference between the highest and lowest counts in each cornea as a percentage of the mean cell count for that cornea. The cell count scatter in 97 corneas varied between 3 and $39 \%$, with a mean value of $14.3 \%$. The influence of subject age and mean cell count on the count scatter in individual corneas is shown in Tables 1 and 2 .

Table 1 Subject age and count scatter

\begin{tabular}{lll}
\hline & $\begin{array}{l}\text { Under } 50 \text { years old } \\
(40 \text { eyes })\end{array}$ & $\begin{array}{l}50 \text { years and over } \\
(40 \text { eyes })\end{array}$ \\
\hline $\begin{array}{l}\text { Cell count scatter } \\
\text { (mean) }\end{array}$ & $12.3 \%$ & $14.7 \%$ \\
& $(8.1 \text { photos })^{*}$ & $(7.7$ photos $) *$ \\
\hline
\end{tabular}

*Mean number of photographs counted per cornea

Table 2 Mean cell count and count scatter

\begin{tabular}{lll}
\hline & $\begin{array}{l}\text { Less than } 2500 \text { cells } / \mathrm{mm}^{2} \\
\text { (40 eyes) }\end{array}$ & $\begin{array}{l}2500 \mathrm{cells} / \mathrm{mm}^{2} \text { and over } \\
(40 \mathrm{eyes})\end{array}$ \\
\hline $\begin{array}{l}\text { Cell count } \\
\begin{array}{l}\text { Scatter } \\
\text { (mean) }\end{array}\end{array}$ & $15.6 \%$ & $12.4 \%$ \\
\hline
\end{tabular}

* Mean number of photographs counted per cornea 


\section{Discussion}

The technique of endothelial cell counting proved to be highly reproducible when 16 eyes were rephotographed and recounted after an average interval of 7 weeks. Validation of the counting technique is important because the number of cells included in each photograph (40 to 100 ) is extremely small compared with the total endothelial population of approximately 400000 cells (Svedberg and Bill, 1972). Furthermore, there can be considerable regional variations in cell size, particularly in older corneas with a low cell density. Finally, it is impossible to be certain that each of the 7 to 10 photographs taken per cornea represents a different area of cells. In practice the involuntary small eye movements of the subject are relied upon to achieve random sampling of the endothelium.

It is technically most convenient to photograph and count the endothelial cells in the axial region, which is clinically the most important part of the cornea. However, the assumption that the axial cell count is representative of the cell density elsewhere in the endothelium has until now never been substantiated. Indeed Irvine (1956) found that the endothelial cell concentration in the centre of the cornea was between 6 and $48 \%$ (average $16 \%$ ) less than at the periphery. He counted endothelial cell nuclei in flat corneal sections from necropsy eyes, however, so that post mortem changes and preparation artefacts cannot be excluded. In the present study peripheral and axial cell counts obtained in vivo showed much closer agreement, the axial count being on average only $3 \cdot 2 \%$ lower than the peripheral (nasal and temporal) count. Thus axial cell counts provide a good indication of the total endothelial cell density in the normal cornea. However, following trauma such as that caused by lens extraction, for example, endothelial cell loss is almost certainly unevenly distributed, and axial photography alone cannot be relied upon to quantitate the total endothelial cell population.

Although there is considerable variation in the cell count between individuals of the same age, the variation between the 2 normal eyes of any one individual is extremely small. This raises the possibility of quantitating retrospectively the effects of uniocular trauma on the endothelial cell population by using the unaffected, and presumably normal, eye as a control. Thus, if a traumatised eye required further surgery, knowledge of the cell loss already sustained might influence the choice of surgical procedure.

The gradual decrease in endothelial cell count with increasing age which this study has shown confirms the findings of other workers (Bourne and
Kaufman, 1976a; Laing et al., 1976a). An earlier histological study of necropsy eyes had failed to show any clear correlation between endothelial cell density and age (Irvine and Irvine, 1953). The reduced cell counts found in older subjects implies that over the years there occurs a gradual loss of cells which the endothelium cannot adequately replace. Indeed, available evidence suggests that if endothelial cell division does occur in man it is very infrequent (Kaufman et al., 1966). Thus the concept that the corneal endothelial cell reserve is limited should be constantly borne in mind during any surgical manipulations within the anterior chamber.

The normal endothelial cell count varies within wide limits in all age groups so far investigated. Thus some subjects with apparently normal corneas may have cell counts which are between 800 and 1000 cells $/ \mathrm{mm}^{2}$ less than counts in other subjects of the same age. In practical terms this means that the occurrence of diffuse cell loss in a cornea with an initially high cell density might not be detected by a cell count unless the loss was excessive. However, cell loss may be suspected in the presence of marked cell pleomorphism (Sturrock, personal observation). Furthermore, unilateral cell loss can be readily diagnosed by demonstrating a higher count in the fellow eye.

On the assumption that the lower cell counts found in older corneas are indeed due to the gradual loss of cells throughout life it is interesting to speculate why adult corneas of the same age should show such a wide range of endothelial cell densities. This variation may simply reflect a similar variation in cell density already present at birth. Alternatively, the rate at which cells 'drop out' over the years may vary from one individual to another. This would presuppose less variation in endothelial cell density in infants, but specular microscopy has not yet been performed in this age group. Long-term follow-up studies to document changes in cell density occurring in individuals over periods of years would be of considerable interest. Whether the apparent cell loss is genetically predetermined or results from environmental influences such as subtle alterations in aqueous composition and circulation remains to be investigated.

In vivo corneal specular microscopy has now been established as a practical and reliable method for determining endothelial cell density. There are, however, certain limitations to the use of the specular microscope.

Although the technique is fairly simple, counting endothelial cells is time-consuming. However, if the specular microscope is used merely for in vivo examination of the endothelium (without taking photographs for subsequent cell counting) it is not 
always possible to visualise the cells adequately owing to constant small movements of the eye in some subjects. Then it is necessary either to take photographs which can be studied later or use a suction contact lens (Laing et al., 1975), but the latter restricts the examination to the centre of the cornea.

The information obtained from specular microscopy is basically morphological and gives little indication of the functional capacity of the endothelium to maintain corneal deturgescence. Furthermore, absolute cell counts are of limited value, since the minimum cell density compatible with corneal clarity is unknown, and indeed this hypothetical figure probably depends upo: the health or 'pumping capacity' of the cells. It has been found that the cornea can remain thin and clear when the axial cell density has fallen to less th:n $500 / \mathrm{mm}^{2}$ (Bourne and Kaufman, 1976b; Binkhorsi et al., 1977).

It would clearly b? of great interest to be able to study selected areas of enciothelial cells over prolonged periods of time (days or weeks). Although the changing appearance of individual cells in the rabbit endothelium have been followed in vivo for periods of up to 9 hours (Sherrard, 1976), in vivo studies in man are impracticable owing to the combination of high magnification, eye movement, and the relative uniformity of the endothelium, which make orientation impossible.

Lastly it is possible to perform specular microscopy only when the cornea is optically clear. Thus the presence of oedema, scarring, or infiltration of the cornea precludes examination of the underlying endothelium. The precise role of corneal endothelial specular microscopy in clinical ophthalmology has yet to be defined, but it clearly represents a significant advance in our ability to study this vital layer of cells.

Statistical analysis of the cell counts was performed by $\mathrm{Mr} \mathrm{H}$. Donovan, Institute of Ophthalmology. Thanks are due to Professor Barrie Jones for permission to examine and photograph patients under his care.

\section{References}

Binkhorst, C. D., Loones, L. H., and Nygaard, P. (1977). The clinical specular microscope. Documenta Ophthalmologica, 44, 57-75.

Bourne, W. M., and Enoch, J. M. (1976). Some optical principles of the clinical specular microscope. Investigative Ophthalmology, 15, 29-32.

Bourne, W. M., and Kaufman, H. E. (1976a). Specular microscopy of human corneal endothelium in vivo. American Journal of Ophthalmology, 81, 319-323.

Bourne, W. M., and Kaufman, H. E. (1976b). Endothelial damage associated with intraocular lenses. American Journal of Ophthalmology, 81, 482-485.

Bourne, W. M., and Kaufman, H. E. (1976c). Cataract extraction and the corneal endothelium. American Journal of Ophthalmology, 82, 44-47.

Bourne, W. M., McCarey, B. E., and Kaufman, H. E. (1976). Clinical specular microscopy. Transactions of the American Academy of Ophthalmology and Otolaryngology, 81, 743753.

Irvine, A. R. (1956). The role of the endothelium in bullous keratopathy. Archives of Ophthalmology, 56, 338-351.

Irvine, A. R., and Irvine, A. R. (1953). Variations in normal human corneal endothelium. American Journal of Ophthalmology, 36, 1279-1285.

Kaufman, H. E., Capella, J. A., and Robbins, J. E. (1966). The human corneal endothelium. American Journal of Ophthalmology, 61, 835-841.

Laing, R. A., Sandstrom, M. M., and Leibowitz, H. M. (1975). In vivo photomicrography of the corneal endothelium. Archives of Ophthalmology, 93, 143-145.

Laing, R. A., Sandstrom, M. M., Benospi, A. R., and Leibowitz, H. M. (1976a). Changes in the corneal endothelium as a function of age. Experimental Eye Research, 22, 587-594.

Laing, R. A., Sandstrom, M. M., Benospi, A. R., and Leibowitz, H. M. (1976b). Morphological changes in corneal endothelial cells after penetrating keratoplasty. American Journal of Ophthalmology, 82, 459-464.

Maurice, D. M. (1968). Cellular membrane activity in the corneal endothelium of the intact eye. Experientia, 24, 1094-1095.

Sherrard, E. S. (1976). The corneal endothelium in vivo its response to mild trauma. Experimental Eye Research, 22 347-357.

Svedberg, B., and Bill, A. (1972). Scanning electron microscopic studies of the corneal endothelium in man and monkeys. Acta Ophthalmologica, 50, 321-336.

Vogt, A. (1919). Die Sichtbarkeit des lebenden Hornhautendothels im Lichtbüschel der gullstrandschen Spaltlampe. Klinische Monatsblätten für Augenheilkunde, 63, 233-234. 